\title{
HERZIENING VAN CONVERSIEKOERSEN BIJ VOORKEURSEMISSIES
}

\author{
door Dr A. I. Diepenhorst
}

In het emissieprospectus van de na de tweede wereldoorlog geëmitteerde converteerbare obligatieleningen treft men steeds weer een bepaalde clausule aan, die weliswaar geen novum vormt omdat ze ook bij vroegere leningsvoorwaarden incidenteel werd opgenomen, maar die thans wel als „,conditio sine qua non" beschouwd schijnt te worden. Als voorbeeld citeren wij hier lid 6 van artikel 6 uit de bepalingen der Trustacte, verleden op 10 November 1951 voor Notaris W. W. Rutgers, te Amsterdam, inzake de $41 / 2 \%$ converteerbare obligatielening groot $f$ 20.000.000. ten laste der Algemene Kunstzijde Unie N.V. te Arnhem.

.Telkens indien de Algemene Kunstzijde Unie N.V. voor 1 Januari 1959 mocht overgaan tot uitgifte van gewone aandelen met recht van voorkeur voor de houders van de alsdan uitstaande gewone aandelen of tot uitgifte van gewone aandelen als bonusaandelen of als dividend, zal de conversiekoers worden verlaagd tot een koers, berekend op de navolgende wijze.

De nieuwe conversiekoers wordt bepaald op de tot het naastbij gelegen gehele getal naar beneden afgeronde uitkomst, welke verkregen wordt door de som van:

a. het product van het vóór de uitgifte uitstaande nominale gewone kapitaal der Algemene Kunstzijde Unie N.V. en de alsdan geldende conversiekoers en

b. het product van het nominale bedrag der nieuw uit te geven gewone aandelen en de koers van uitgifte te delen door het nominale bedrag van het dadelijk na de uitgifte uitstaande gewone kapitaal der Algemene Kunstzijde Unie N.V. De koers van uitgifte als in dit lid onder $b$. bedoeld wordt bij uitgifte van bonusaandelen aangenomen op nihil, en bij uitgifte van aandelen als dividend op 100".

De hier gebezigde clausule is in de Amerikaanse financieringsliteratuur bekend als de ,,anti-dilution clause". Men doet er echter goed aan die ,bekendheid" met een korreltje zout te nemen. Er zijn slechts weinig auteurs die aan deze clausule aandacht schenken, en zelfs dan volstaat men veelal met een blote vermelding. Het directe doel van dergelijke clausules wordt intussen goed door de Amerikaanse benaming aangegeven: het gaat om een bescherming van de houders van converteerbare obligaties tegen aantasting door waardevermindering, tegen verwatering dus, van het hen oorspronkelijk toegekende recht. De herziening van de conversiekoers moet worden beschouwd als een compensatie voor de ten gevolge van voorkeursemissie opgetreden verkleining van de waarde van dat recht.

Teneinde te kunnen nagaan in hoeverre de toepassing van de door de clausule voorgeschreven techniek tot resultaten leidt welke aan het doel beantwoorden, willen wij gebruik maken van een eenvoudige algebraische analyse, waarbij wij dezelfde symbolen zullen bezigen als in onze algemene theorie van de claimwaarde ${ }^{1}$ ).

Dit biedt het voordeel, dat de daarin reeds geformuleerde relaties tussen de ook voor dit vraagstuk relevante grootheden zonder meer kunnen worden overgenomen.

1) Algemene theorie van de claimwaarde, M.A.B. 1954 pag. 299 e.v. 
Uitgangspunt vormt een onderneming, waarvan het aantal geplaatste en volgestorte aandelen, met een nominale waarde van $f 1000,-$, b bedraagt, terwijl de totale beurswaarde van dit vermogen a' groot is. Ten laste van deze onderneming staat uit een a pari geëmitteerde converteerbare obligatielening, warvoor de conversiekoers (laatstelijk) bepaald is op $k^{\prime}$. De onderneming wenst aan nieuw aandelenvermogen aan te trekken een reëel bedrag groot $c$. Ten gevolge van deze emissie verandert de totale beurswaarde van $a^{\prime}$ tot $a$. Vindt deze emissie tegen de voorkeurskoers $\frac{e}{10}$ plaats, dan is herberekening van de conversiekoers $k^{\prime}$ volgens de ,,anti-dilution" clausule tot $k$ voorgeschreven. In bijgaand schema zijn deze aangenomen waarden en de daaruit af te leiden waarden gerubriceerd.

In het geval van vrije emissie tegen de maximale emisiekoers $\frac{a-c}{10 b}$ vindt geen herberekening van de conversiekoers plaats. De gedachte welke hieraan ten grondslag ligt kan zijn, dat in dit geval geen aantasting van de waarde van het conversierecht heeft plaats gevonden, maar ook die, dat voor deze aantasting geen compensatie gegeven behoeft te worden. Wij komen hierop aanstonds nog terug, maar thans kan reeds worden vastgesteld, dat de herberekening welke bij vrije emissie tegen de voorkeurskoers e wél voortgang vindt, dus blijkbaar beoogt de waarde van het conversierecht gelijk te doen zijn aan die welke dit bij vrije emissie tegen maximum emissiekoers gehad zou hebben.

In symbolen uitgedrukt:

$$
\frac{100}{k} \times \frac{a e}{c+e b}=\frac{100}{k^{\prime}} \times \frac{a-c}{b}
$$

Substitueert men nu voor

$$
k=\frac{b k^{\prime}+\frac{c}{e} \cdot \frac{e}{10}}{b+\frac{c}{e}}
$$

dan volgt hieruit, na vereenvoudiging en oplossing naar $k^{\prime}$

$$
\mathrm{k}^{\prime}=\frac{\mathrm{a}-\mathrm{c}}{10 \mathrm{~b}} \begin{aligned}
\text { als } \mathrm{c} & \neq 0 \\
\mathrm{e} & \neq 0 \\
\mathrm{c}+\mathrm{be} & \neq 0
\end{aligned}
$$

Op het eerste gezicht schijnt het, dat de herberekening van de conversiekoers, wil ze haar compenserend effect bereiken, van een vrij zinloze veronderstelling uitgaat:

de conversiekoers zou (laatstelijk) bepaald dienen te zijn op een grootte die juist gelijk is aan de maximum-koers waartegen men thans aandelen zou kunnen emitteren tot een totaal reëel bedrag c.

Richten wij thans onze aandacht op de vrije emissie tegen de maximum emissiekoers. Zoals reeds werd opgemerkt kan het in dit geval ongewijzigd laten van de conversiekoers wellicht $z$ ijn verklaring vinden in de veronderstelling, dat van een daling van de waarde van het conversierecht hier geen sprake is. Dit zou dus betekenen dat 


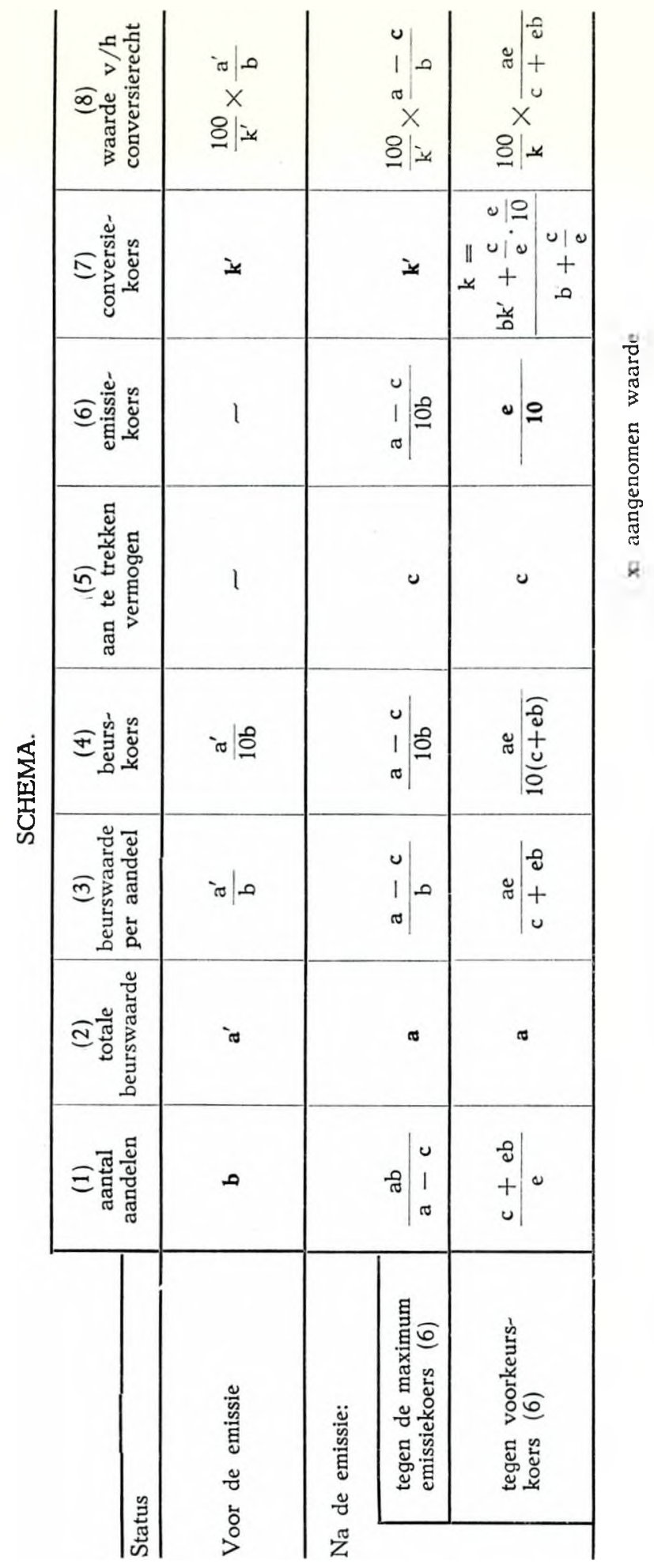

m a b blz. 295 


$$
\frac{100}{k^{\prime}} \times \frac{a^{\prime}}{b^{-}}=\frac{100}{k^{\prime}} \times \frac{a-c}{b}
$$

hetgeen het geval zal zijn wanneer $a^{\prime}=a-c$, of

$$
a=a^{\prime}+c
$$

Men zou hier dus blijkbaar uitgaan van de veronderstelling van de „rentabiliteitswaarde" 2) theorie of die van de intrinsieke waardetheorie. zoals die met betrekking tot de theorie van de claimwaarde zijn opgesteld. Het eerste komt ons, gezien de houding van de practijk met betrekking tot de bepaling van de theoretische claimwaarden, wel het meest waarschijnlijk voor. Vervolgens kan worden vastgesteld, dat wanneer de in de clausle omschreven techniek juist zou zijn, herberekening van de conversiekoers in die gevallen waarin herberekening niet nodig is, tot het terugvinden van de oorspronkelijke conversiekoers zou moeten leiden. Dit impliceert niets anders dan dat

$$
\mathrm{k}^{\prime}=\frac{\mathrm{bk}^{\prime}+\frac{\mathrm{c}}{\frac{\mathrm{a}-\mathrm{c}}{\mathrm{b}}} \times \frac{\mathrm{a}-\mathrm{c}}{10 \mathrm{~b}}}{\mathrm{~b}+\frac{\mathrm{c}}{\frac{\mathrm{a}-\mathrm{c}}{\mathrm{b}}}}
$$

hetgeen na vereenvoudiging en oplossing naar $k^{\prime}$ oplevert $k^{\prime}=\frac{a-c}{10 b}$

$\mathrm{Nu}$ bleek echter zo juist voor het besproken geval te gelden de veronderstelling $\mathrm{a}=\mathrm{a}^{\prime}+\mathrm{c}$, zodat het gevonden resultaat ook mag worden geschreven

$$
\mathrm{k}^{\prime}=\frac{\mathrm{a}^{\prime}}{10 \mathrm{~b}}
$$

Wij zijn van mening, dat thans de nevel rondom de ,anti-dilution" clausule begint op te trekken. De vroeger gevonden en zinloosschijnende voorwaarde voor de juistheid van de herberekeningstechniek krijgt thans enige zin, waarmede wij overigens nog niet willen zeggen dat wij ze ook aanvaardbaar achten.

Het blijkt dus dat herberekening van de conversiekoers leidt tot compensatie van de waardedaling van het oorspronkelijke conversierecht, wanneer men uitgaat van de volgende veronderstellingen:

1. De beurswaarde van een aandeel is evenredig met de verwachte dividenduitkering.

2. Het nieuw aangetrokken vermogen zal de voor dividenduitkering beschikbare som terstond verhogen met een bedrag dat, uitgedrukt in procenten van het reëel gevraagde bedrag, gelijk is aan het rendementspercentage van de aandelen voor de emissie.

3. Op het moment van emissie van aandelen met voorkeursrecht voor

2) Wij vestigen er de aandacht op, dat de betiteling: "rentabiliteitswaarde"-theorie hier in een speciale betekenis wordt gebezigd. Men zie in dezen ons naschrift bij P. G. van de Vliet: Algemene theorie van de Claimwaarde, M.A.B. 1954, pag. 469. 
oude aandeelhouders is de (laatstelijk) vastgestelde conversiekoers juist gelijk aan de beurswaarde van een aandeel.

Tegen de aanvaardbaarheid van de tweede voorwaarde hebben wij onze bezwaren reeds vroeger uiteen gezet 3 ); wij kunnen ons dus tot de derde beperken, waar de eerste ons volkomen acceptabel voorkomt. De gelijkheid tussen $k^{\prime}$ en $\frac{a^{\prime}}{10 b}$ achten wij weinig waarschijnlijk. Ze zou alleen te realiseren zijn, wanneer men bij het voor de eerste maal vaststellen van de conversiekoers, dus ten tijde van de emissie van converteerbare obligaties, over een wel zeer uitzonderlijk prognostisch vermogen beschikte, of wanneer men zich gedurende de gehele conversieperiode vrijwillig zou onderwerpen aan het impératief, alleen tot voorkeursemissie van aandelen over te gaan, wanneer de beurskoers gelijk zou zijn aan de conversiekoers. Ook dit laatste komt ons vrij ongeloofwaardig voor.

Hiermede is intussen de zaak nog niet afgedaan. Wat te denken van de gelijkheid als fictie? Het gaat hierbij dus om herberekening alsof de gelijkheid bestond, terwijl ze duidelijk nièt bestaat. Veronderstellen wij allereerst $k^{\prime}<\frac{a^{\prime}}{l \bar{b} b}$. In dit geval heeft de koers van het aandeel het conversieniveau overschreden; er is een effectieve conversiemogelijkheid, waarvan echter niet door alle houders van converteerbare obligaties is gebruik gemaakt. Herberekening leidt thans tot een conversiekoers waar in de waardedaling van het oorspronkelijke conversierecht niet ten volle wordt gecompenseerd. Men zou dit kunnen interpreteren als een straf op de zonde: dan had men maar tijdig moeten converteren. Die straf komt echter te laat, terwijl ze bovendien de conversiemogelijkheid voor de toekomst verkleint.

Is echter op het moment van emissie $k^{\prime}>\frac{\mathrm{a}^{\prime}}{10 \mathrm{~b}}$, dan wordt door de herberekening een zekere overcompensatie verleend, die de conversie-mogelijkheid voor de toekomst vergroot. Inderdaad is zo een correctie van een indertijd blijkbaar te hoog gestelde conversiekoers mogelijk. Het is echter de vraag, of er geen andere en betere correctiemethoden zijn te vinden dan de aan bepaalde tijdstippen en een vaste formule gebonden vorm welke de clausule aangeeft.

Samenvattend kan dus ons oordeel over de gangbare clausule weinig gunstig luiden. Haar onbewuste veronderstellingen welke wij hebben getracht te formuleren, komen ons niet aanvaardbaar voor. Ook van de fictie verwachten wij niets.

Wij willen ten slotte trachten, een procedure te ontwikkelen, die los van bijzondere veronderstellingen de houders van converteerbare obligaties compensatie biedt tegen aantasting van de waarde van hun conversierecht bij voorkeursemissie.

Deze compensatie zal slechts betrekking behoeven te hebben op de extra-daling welke de waarde van het conversierecht ondervindt ten gevolge van emissie tegen een lagere koers dan de maximum-emissiekoers. Het zou immers onbillijk zijn, aan houders van converteerbare obligaties een grotere compensatie te verlenen dan aan aandeelhouders.

Derhalve zal $\mathrm{k}$ zo moeten worden bepaald dat

$$
\frac{100}{k^{\prime}} \times \frac{a-c}{b}=\frac{100}{k} \times \frac{a e}{c+e b}
$$

3) Algemene theorie van de claimwaarde, M.A.B. 1954 pag. 311. 
$\mathrm{Nu}$ is $\frac{a-c}{b}$ gelijk aan de maximum emissieprijs, die wij ter vereenvoudiging $m$ willen noemen, terwijl $\frac{a e}{c+e b}$ gelijk is aan de beurswaarde na emissie, welke wij met $n$ willen aanduiden.

$\mathrm{Na}$ deze vereenvoudiging kan de gelijkheid worden geschreven als

$$
\frac{100}{\mathrm{k}^{\prime}} \times \mathrm{m}=\frac{100}{\mathrm{k}} \times \mathrm{n}
$$

Oplossing van $\mathrm{k}$ levert op

$$
\mathrm{k}=\frac{\mathrm{k}^{\prime} \mathrm{n}}{\mathrm{m}}
$$

Echter is $m=n+R$ ) zodat de herberekeningsformule luidt:

$$
\mathrm{k}=\frac{\mathrm{k}^{\prime} \mathrm{n}}{\mathrm{n}+\mathrm{R}}
$$

In woorden uitgedrukt: de nieuwe conversieverhouding wordt gevon den door de laatstelijk bepaalde conversieverhouding te vermenigvuldigen met de beurswaarde van een aandeel na de emissie, en de verkregen uitkomst vervolgens te delen door de som van deze beurswaarde en de beurswaarde van een claim.

Er blijft nog maar één moeilijkheid over. Hoe moet de quantitatieve voorstelling van ., de beurswaarde van een aandeel na de emissie" en van "de beurswaarde van een claim" worden gegeven?

Persoonlijk zouden wij hier kiezen voor gewogen gemiddelden, met de omzet als wegingscoëfficient van de gemiddelde dagelijkse notering, over een periode welke gelijk is aan die gedurende welke de aandelen ex-claim en de claims ter beurze verhandeld werden. De invloed van het toeval is met deze weging zeker niet geécarteerd, maar dat mag de houder van een converteerbare obligatie, die toch eigenlijk een soort van „,aandeel-larve" houdt, ook niet verwachten. Hij is anderzijds echter ook weer geen echte aandeelhouder; hij houdt zich nog op de vlakte. Daarom is het ook billijk de invloed van het toeval iets te vervlakken, en daaraan komt de voorgestelde wijze van herberekening van de conversiekoers onzes inziens in voldoende mate tegemoet.

\section{Summary.}

First of all the conceptions on which is based the generally-used ,antidilution" clause, which aims at protecting the right of conversion of the holders of convertible debentures against the dilution which might result from a preferential issue of shares.

It appears that this clause will only lead to the consequences desired if the following three requirements are satisfied.

1. The market value of a share is, c.p., directly proportional to the expected distribution of dividend.

4) $\mathrm{R}$ representeert hier de theoretische waarde van de claim. 
2. The newly acquired capital will increase the sum distributable for dividend with an amount which, expressed in percentages of the actually asked amount equals the return percentage of the shares before the issue.

3. At the moment of issue of shares with preferential right to old shareholders the (lastly) fixed conversion price exactly equals the market price of a share.

These requirements will as a rule not be satisfied, in which case the recalculation does not lead to the results desired. In view of this a new revision clause is proposed which runs;

In the case of a preferential issue of shares the new rate of conversion is formed by multiplying the lastly fixed rate of conversion with the market price of a share after the issue and by dividing the result by the sum of this market price and the price of a right. As regards the quantification of the market price of a share after the issue and of the price of a right a choice is made in favour of a weighted average the volume of the sales being the weighting coefficient, of the average daily quotation over a period equalling the period during which the rights were dealt in.

\section{Résumé.}

L'auteur étudie d'abord les principes qui sont à la base de la clause usuelle dite d',,anti-dilution", clause qui veut protéger le droit de conversion des porteurs d'obligations convertibles contre un arrosage du capital qui pourrait résulter d'une émission préférentielle d'actions.

Pour que cette clause soit opérante, il faut que soient remplies trois conditions, à savoir:

1. Que la valeur boursière d'une action soit, toutes choses égales par ailleurs, proportionnelle à la distribution des dividendes attendue;

2. Que le nouveau capital attiré augmente la somme destinée à la distribution des dividendes d'un montant qui, exprimé en pourcentage du montant réellement demandé, est égal au pourcentage du rendement des actions avant l'émission;

3. Qu'au moment de l'émission d'actions assorties d'un droit préférentiel pour les anciens actionnaires, le cours de conversion soit exactement égal à la valeur boursière d'une action.

En général, ces conditions ne sont pas remplies, tandis que la révision ne conduit pas non plus aux résultats désirés.

Cela étant, l'auteur propose une nouvelle formule de révision: En cas d'une émission préférentielle d'actions, le nouveau rapport est calculé en multipliant le dernier rapport de conversion par la valeur boursière d'une action après l'émission; le produit ainsi obtenu est ensuite divisé par la somme de la valeur boursière de l'action après émission et la valeur du droit de souscription. En ce qui concerne la quantification de la valeur boursière de l'action après l'émission et celle de la valeur du droit, on choisit pour critère une moyenne pondérée de la cotation, moyenne journalière d'une période égale à celle pendant laquelle les droits sont négociés en bourse. Comme coefficient de pondération, on prend le chiffre d'affaires. 